\title{
Molecular cloning and characterization of $\alpha 1$-soluble guanylyl cyclase gene promoter in rat pituitary cells
}

\author{
Yonghua Jiang and Stanko S Stojilkovic \\ Section on Cellular Signaling, Endocrinology and Reproduction Research Branch, NICHD, National Institutes of Health, Bethesda, Maryland 20892-4510, USA \\ (Requests for offprints should be addressed to S S Stojilkovic; Email: stojilks@mail.nih.gov)
}

\begin{abstract}
Soluble guanylyl cyclase is a cytosolic enzyme which catalyzes conversion of GTP to the second messenger cyclic GMP. The transcriptional regulation at the promoter levels of four soluble guanylyl cyclase subunits, termed $\alpha 1, \alpha 2, \beta 1$, and $\beta 2$, is largely unknown. In this study, we identified the transcription start site of $\alpha 1$-soluble guanylyl cyclase gene in rat pituitary cells and cloned the $3.5 \mathrm{~kb} 5^{\prime}$-promoter. Sequence analysis of this TATA-less promoter revealed the presence of several putative-binding sites for transcriptional factors, including CCAAT site at -41 to -32 and Sp1 site at -34 to -24 . Transfection of pituitary cells with constructs of variable lengths confirmed the relevance of different promoter regions in the control of transcriptional activity. Among them, the -49 to +156 region was critical for basal transcriptional activity. Electrophoretic mobility shift assay using nuclear proteins extracted from normal and immortalized pituitary cells indicated that the CCAAT/Sp1 site within the -49 to +156 region was able to specifically interact with CCAAT-binding factor and Sp1. These two sites were partly overlapped and both of them conferred stimulatory effects. The in vivo recruitment of CCAAT-binding factor and Sp1 was confirmed by chromatin immunoprecipitation. These results indicate that the composite CCAAT/Sp1 cis-element contributes to the expression of $\alpha 1$-sGC subunit in resting pituitary cells.
\end{abstract}

Journal of Molecular Endocrinology (2006) 37, 503-515

\section{Introduction}

Soluble guanylyl cyclase (sGC; E.C.4.6.1.2) catalyzes the formation of cGMP, an intracellular messenger that activates several downstream effectors, including ion channels, protein kinase $\mathrm{G}$, and phosphodiesterases (Garbers et al. 1994). This signaling pathway regulates a broad spectrum of physiological processes, such as smooth muscle relaxation, platelet aggregation, and neuronal cell mobility. Based on cDNA cloning, four sGC subunits have been identified and termed $\alpha 1, \alpha 2, \beta 1$, and $\beta 2$. The human isoforms isolated from an adult brain library, termed $\alpha 3$ and $\beta 3$, represent the human homologues of rat and bovine $\alpha 1$ and $\beta 1$ (Zabel et al. 1998). The $\alpha 1$ and $\alpha 2$ subunits are interchangeable in terms of sGC activity when coexpressed with $\beta 1$, but the $\alpha 1 \beta 1$ heterodimer is most common in mammalian tissues (Hanafy et al. 2004). The dimer activity is regulated directly at protein level. Physiologically, the most relevant mode of such regulation is mediated by binding of nitric oxide (NO) to the heme group of sGC (Humbert et al. 1990). The enzyme is also subjected to phosphorylation by protein kinase, src-like kinases, and protein kinases C and G (Pyriochou \& Papapetropoulos 2005). Proteinprotein interactions also contribute to the direct control of sGC activity, since documented by interaction between the chaperonin containing t-complex polypeptide subunit $\eta$ and $\beta 1$-sGC, which leads to inhibition of the enzyme activity (Hanafy et al. 2004).

Journal of Molecular Endocrinology (2006) 37, 503-515

0952-5041/06/037-503 $\quad$ C) 2006 Society for Endocrinology Printed in Great Britain
Several reports also indicate that the regulation of sGC activity occurs indirectly, at transcriptional and post-transcriptional levels, affecting the availability of sGC subunits and the total number of functional heterodimers. For example, the steady-state sGC subunits mRNA levels are reduced by treatments with estrogens (Krumenacker et al. 2001), lipopolysaccharide (Pedraza et al. 2003), and $\beta$-amyloid peptides (Baltrons et al. 2002). In human mesangial cells, collagen type I can also reduce the steady-state $\beta 1$-sGC mRNA levels and such reduction occurs at transcriptional level (De Frutos et al. 2005). On the other hand, the AU-rich elements identified in the 3 '-untranslated region of $\alpha 1$ - and $\beta 1$-sGC mRNAs provide sites for posttranscriptional regulation by cAMP (Kloss et al. 2004). Differential expression of mRNAs for $\alpha$ and $\beta$-sGC also influences the formation of functional heterodimers. For example, in pituitary cells, the mRNA levels (Budworth et al. 1999) and the protein levels (Kostic et al. 2004) for $\alpha 1$-sGC are lower than $\beta 1$-sGC. Consistent with these findings, the overexpression of $\alpha 1$-sGC alone in immortalized pituitary cells is sufficient to make several fold increase in NO-stimulated cGMP production (Kostic et al. 2004).

Changes in the mRNA expression levels of sGC subunits have also been reported in several disease models. In aortic tissue from spontaneously hypertensive rats, the vasodilator response to an $\mathrm{NO}$ donor was markedly attenuated compared with normotensive rats

DOI: $10.1677 / j m e .1 .02180$ Online version via http://www.endocrinology-journals.org 
(Bauersachs et al. 1998). The detailed analysis of hypertensive animals revealed that $\alpha 1$ - and $\beta 1$-sGC mRNA levels, as well as $\beta 1$-sGC protein levels, were reduced significantly, indicating that vasodilator dysfunction is related to the $s G C$ gene expression (Kloss et al. 2000). In deoxycorticosterone acetate-salt model of rat hypertension, the protein expression level of $\beta 1$-sGC was also decreased in the inner medulla (Taylor et al. 2003). In addition, the protein levels of $\beta 1$-sGC were reduced in reactive astrocytes obtained from Alzheimer, Creutzfeldt-Jakob, and multiple sclerosis patients (Baltrons et al. 2004), whereas an upregulation of sGC was observed in aortas from rats with chronic heart failure (Bauersachs et al. 1999). Therefore, studies on the transcriptional regulation of sGC are not only important for understanding the mechanism of $s G C$ gene expression, but are also clinically relevant.

However, the knowledge on promoter of $s G C$ genes and regulation of the enzyme activity at transcriptional and post-transcriptional levels is very deficient. At the present time, the genomic organization of mouse (Sharina et al. 2000) and medaka fish (Mikami et al. 1999) $\alpha 1$ - and $\beta 1$-sGC subunits, and human $\beta 1$-sGC subunit (Sharina et al. 2003) has been reported. Among the mammalian species, only the mouse $\alpha 1$-sGC promoter has been cloned, but its cis-elements have not been experimentally identified (Vazquez-Padron et al. 2004). Furthermore, the finding that $\alpha 1$-sGC gene for mouse has only 56 and $45 \%$ homology with predicted sequences for rat and human genes respectively (Vazquez-Padron et al. 2004), clearly indicates a need for cloning of promoter regions in other species in order to understand the variability in their structures and regulation of transcriptional activity. Here, we describe the promoter region of rat $\alpha 1$-sGC gene. Using pituitary tissue, we identified the transcriptional start site and cloned a $3.5 \mathrm{~kb}$ upstream promoter of the $\alpha 1$-sGC subunit. We also identified numerous binding sites for transcriptional factors by means of sequential analysis of the $\alpha 1$-sGC promoter region. Partly overlapping cis-elements CCAAT and Sp1 were further identified by the electrophoretic mobility shift assay (EMSA) and chromatin immunoprecipitation (ChIP), whereas the site-directed mutagenesis study indicated that this site regulates the expression of $\alpha 1-s G C$ gene in resting cells.

\section{Materials and methods}

\section{Materials}

Medium 199, Ham's F12K medium, Opti-MEM, penicillin, horse serum, streptomycin, and gentamicin stock solution were purchased from Invitrogen. Fetal bovine serum was obtained from Biosource International (Camarillo, CA, USA). DNA oligonucleotides were synthesized by Integrated DNA Technologies (Coralville,
IA, USA) and the nucleotide sequences are listed in Table 1 and Fig. 6. Antibodies against CCAATbinding factor (CBF)-A (SC-13045), CCAAT/enhancerbinding protein $\beta$ (SC-746), nuclear factor-1 (NF-1) (SC-870), and Sp1 (SC-14027) were purchased from Santa Cruz Biotechnology (Santa Cruz, CA, USA). Other reagents were obtained from Sigma, if not otherwise specified.

\section{Cell cultures}

Anterior pituitaries were removed from adult female Sprague-Dawley rats obtained from Tacoma Farms (Germantown, NY, USA) and dispersed as described previously (Kostic et al. 2002). Dispersed cells were cultured for $24 \mathrm{~h}$ in medium 199 containing Earle's salts, sodium bicarbonate, $10 \%$ horse serum, and penicillin $(100 \mathrm{U} / \mathrm{ml})$ and streptomycin $(100 \mu \mathrm{g} / \mathrm{ml})$. Lacto-somatotroph $\mathrm{GH}_{3}$ immortalized cells and MH1C1 liver cells were maintained in Ham's F12K medium supplemented with $1.5 \mathrm{~g} / 1$ sodium bicarbonate, $15 \%$ heat-inactivated horse serum, $2.5 \%$ fetal bovine serum, and gentamicin $(100 \mu \mathrm{g} / \mathrm{ml})$.

\section{Identification of the transcription start site of $\alpha 1$-sGC gene}

Total RNA was extracted from normal anterior pituitary cells using Trizol Reagent (Invitrogen) and mRNA was enriched by PolyATtract mRNA Isolation Systems (Promega). Identification of the transcription start site of $\alpha 1$-s $G C$ gene was performed using the SMART RACE kit (Clontech) with minor modifications. Primers sGCaRT, RaceOuter, and RaceInner (Table 1) were designed according to the mRNA sequence of $\alpha 1$-sGC deposited in Genbank (BC085746). Primers BD SMART II A oligo, Universal Primer A Mix, and Nested Universal Primer A were provided in the kit. The sGC first strand cDNA was synthesized by the gene-specific primer sGCaRT and BD SMART II A oligo. Then PCR was conducted with the Universal Primer A Mix and the gene-specific primer RaceOuter. Nested PCR was conducted with the Nested Universal Primer A and the gene-specific primer RaceInner. The PCR product was subcloned by TOPO TA cloning kit (Invitrogen). Plasmid DNA was prepared by QIAprep Spin Miniprep kit (Qiagen) and sequenced by Veritas (Rockville, MD, USA). The distance between transcription start site and start codon was calculated based on cDNA sequence (Lorens et al. 1993, Okita et al. 2003, Salgado et al. 2004). The boundary of exons I and II was defined by aligning cDNA sequence of $\alpha 1$-sGC with the genomic DNA in the corresponding region retrieved from rat genome reference database (http://www.ncbi.nlm.nih. gov/genome/seq/RnBlast.html). 
Table 1 Primer sequences used in this study

\begin{tabular}{|c|c|c|c|}
\hline & Position & Sequence & Annotation \\
\hline \multicolumn{4}{|l|}{ Primer name } \\
\hline sGCaRT & 770 to 793 & AGGAGCGTGCTGAAGCTGTTGAGA & \\
\hline RaceOuter & 550 to 577 & GCCAATGTTCTCTGAAGTGCAAGGTTCA & \\
\hline Racelnner & 337 to 364 & GGAACCTGACCAGGAGCCAGTAAGGAGA & \\
\hline $\mathrm{Pt}(-3 \mathrm{~K})$ & -3529 to -3502 & TCAGGTACCTCAACACGAAGAAAGAGATAATAAGCAC & Kpnl site \\
\hline $\operatorname{Pt}(-2 \mathrm{~K})$ & -2250 to -2224 & TTTGGTACCAGACAGTGAGATTGACAAGCCATTAGC & Kpnl site \\
\hline $\operatorname{Pt}(-875)$ & -875 to -848 & AAGGGTACCTGGATCCTGTAGCTGGCTTTCTTGGCAT & Kpnl site \\
\hline $\operatorname{Pt}(-719)$ & -719 to -702 & CTAGGTACCCGCTCTACCACTGAGCTA & Kpnl site \\
\hline $\operatorname{Pt}(-599)$ & -599 to -582 & AGTGGTACCAGAGTCGATGATGAGTCA & Kpnl site \\
\hline $\operatorname{Pt}(-516)$ & -516 to -500 & AAAGGTACCAGGAGTAACTGGAGTGT & Kpnl site \\
\hline $\operatorname{Pt}(-278)$ & -278 to -258 & CTTGGTACCGAGTAGATTAGCCTCAAAGCT & Kpnl site \\
\hline $\operatorname{Pt}(-165)$ & -165 to -149 & GTCGGTACCAGCTAGTACGAGAGAAA & Kpnl site \\
\hline $\operatorname{Pt}(-49)$ & -49 to -32 & TTGGTACCTTGGAGGACAGCGATTGG & Kpnl site \\
\hline $\operatorname{Pt}(156) \mathrm{R}$ & 137 to 156 & AACTCGAGCATCCGGGCGCAGGTGTCTT & Xhol site \\
\hline CAAT/Sp1UP & -50 to -18 & TTTGGAGGACAGCGATTGGGCGGGGAGCAGGAC & CCAAT/Sp1 \\
\hline CAAT/Sp1DN & -50 to -18 & GTCCTGCTCCCCGCCCAATCGCTGTCCTCCAAA & CCAAT/Sp1 \\
\hline MutCCAAT/Sp1UP & -50 to -18 & TTTGGAGGACAGCGAAAAAGCGGGGAGCAGGAC & Mutated site \\
\hline MutCCAAT/Sp1DN & -50 to -18 & GTCCTGCTCCCCGCTTTTTCGCTGTCCTCCAAA & Mutated site \\
\hline IPt $(-3 K)$ UP & -3506 to -3486 & AGCACAAAACTTCCAGACTCA & \\
\hline IPt(-3K)DN & -3411 to -3392 & GGAACACCCCACTACACAAT & \\
\hline IPt(-1K)UP & -1395 to -1377 & CTCTATAGGAACCCACAGCACAGC & \\
\hline $\mathrm{IPt}(-1 \mathrm{~K}) \mathrm{DN}$ & -1281 to -1258 & TGAATAAAGGTCCACAGGCAGGTA & \\
\hline $\mathrm{IPt}(-165) \mathrm{UP}$ & -165 to -145 & AGCTAGTACGAGAGAAAAGGT & \\
\hline IPt $(-18) \mathrm{DN}$ & -40 to -18 & GTCCTGCTCCCCGCCCAATCGCT & \\
\hline IPt(-63)UP & -63 to -42 & CTGGCTTTGGTGGTTTGGAGGA & \\
\hline IPt(59)DN & 40 to 59 & CCTGGAGGGCTGTGTGTGAG & \\
\hline RTGC1 & 1133 to 1156 & TCTTGTTCTTAGGGTCGCCGTGTG & \\
\hline RTGC2 & 1276 to 1299 & TGCCTTCAGCTTTCCCAACCTCTT & \\
\hline RTactin1 & 312 to 335 & CAACTGGGACGATATGGAGAAGAT & Template: NM_031144 \\
\hline RTactin2 & 493 to 516 & AGAGGCATACAGGGACAACACAGC & \\
\hline
\end{tabular}

Meanings of bold cases are shown in the annotation column. The numbers in the position column represent the distance to the transcriptional start site.

\section{Cloning the $5^{\prime}$-promoter of $\alpha 1$-sGC gene and generation of luciferase deletion constructs}

Genomic DNA was extracted from rat anterior pituitaries by Wizard Genomic DNA purification kit (Promega). To amplify the promoter, PCR was conducted using genomic DNA as template and $\mathrm{Pt}(156) \mathrm{R}$ and $\mathrm{Pt}(-3 \mathrm{~K})$ as primers (Table 1$)$. The downstream primer $\mathrm{Pt}(156) \mathrm{R}$ was designed according to the SMART RACE result and incorporates an XhoI site. The upstream primer $\mathrm{Pt}(-3 \mathrm{~K})$ was designed according to the genomic DNA sequence flanking $\alpha 1-s G C$ gene and incorporates a KpnI site. The PCR product was digested by XhoI and KpnI sequentially, and subcloned into the $\mathrm{XhoI} / \mathrm{KpnI}$ site of pGL3.Basic. The obtained promoter clone was termed pGL3. $(-3 \mathrm{~K})$. Based on the pGL3. $(-3 \mathrm{~K})$ sequence, primers $\operatorname{Pt}(-2 \mathrm{~K}), \operatorname{Pt}(-875), \operatorname{Pt}(-719), \operatorname{Pt}(-599)$, $\mathrm{Pt}(-516), \operatorname{Pt}(-278), \operatorname{Pt}(-165)$, and $\mathrm{Pt}(-49)$ were designed to prepare deletion constructs pGL3. $(-2 \mathrm{~K})$, pGL3. (-875), pGL3.(-719), pGL3. (-599), pGL3. $(-516)$, pGL3. $(-278)$, pGL3. $(-165)$, and pGL3. $(-49)$ respectively (Table 1$)$. In combination with $\mathrm{Pt}(156) \mathrm{R}$, these primers were able to amplify decreased length of $\alpha 1$-sGC promoter. Identities of these promoter constructs were confirmed by sequencing.

\section{Reverse transcription-PCR}

Total RNAs were extracted from the 19th and 40th passages of $\mathrm{GH}_{3}$ cells and the 55th passage of MH1C1 cells using Trizol Reagent (Invitrogen). One microgram RNA was treated with amplification grade DNase I and primed with oligo $(\mathrm{dT})_{20}$ primer to synthesize cDNA using SuperScript III first-strand synthesis supermix (Invitrogen). In mocking experiments, reverse transcription was conducted in the absence of SuperScript III. Fifty microliters of the PCR mixtures contained $1 \mu \mathrm{l}$ cDNA, $1 \mu \mathrm{l}$ of each primer $(10 \mu \mathrm{M}), 3 \mu \mathrm{H}_{2} \mathrm{O}$, and $45 \mu \mathrm{l}$ Platinum blue PCR SuperMix (Invitrogen). PCR was initiated with a denature step at $94{ }^{\circ} \mathrm{C}$ for $30 \mathrm{~s}$, followed with 35 amplification cycles consisted of denature at $94{ }^{\circ} \mathrm{C}$ for $30 \mathrm{~s}$, annealing at $60{ }^{\circ} \mathrm{C}$ for $30 \mathrm{~s}$, and extension at $72{ }^{\circ} \mathrm{C}$ for $30 \mathrm{~s}$. PCR products were stored at $4{ }^{\circ} \mathrm{C}$ until use.

\section{Transient transfection and dual-luciferase assays}

One day before transfection, $\mathrm{GH}_{3}$ and MH1C1 cells were plated in 96-well plates with a density of 0.04 million cells per well. Then $0 \cdot 19 \mu \mathrm{g}$ constructs carrying $5^{\prime}$-promoter of $\alpha 1$-sGC gene and firefly luciferase were 
mixed with $0.01 \mu \mathrm{g}$ renilla luciferase construct pRL. CMV (Promega). The DNA mixture was combined with $0.6 \mu \mathrm{l}$ lipofectamine 2000 (Invitrogen) in $50 \mu \mathrm{l}$ OptiMEM medium according to the manufacturer's instructions. In these studies, pRL.CMV was used as an internal control to monitor the transfection efficiency between experimental groups. Transfection mixture with lipofectamine 2000 was incubated for $20 \mathrm{~min}$ at room temperature and added to $\mathrm{GH}_{3}$ cells in $100 \mu \mathrm{l}$ OptiMEM medium. After 6-h incubation, the transfection medium was replaced with Ham's F12K medium supplemented with $1.5 \mathrm{~g} / 1$ sodium bicarbonate, $15 \%$ heat-inactivated horse serum, $2.5 \%$ fetal bovine serum, and gentamicin $(100 \mu \mathrm{g} / \mathrm{ml})$. Following 48-h incubation, medium was aspirated and cells were incubated in Ham's F12K medium supplemented with $1.5 \mathrm{~g} / \mathrm{l}$ sodium bicarbonate and $0 \cdot 1 \%$ BSA for an additional $24 \mathrm{~h}$. The measurement of luciferase activity was done using the Dual-Luciferase Reporter Assay System (Promega). Transfected cells were washed in $1 \times$ PBS twice and then dissolved in $5 \mu \mathrm{l}$ passive lysis buffer (Promega). For measuring the firefly luciferase activity, $20 \mu \mathrm{l}$ cell lysate were mixed with $50 \mu \mathrm{l}$ Luciferase Assay Reagent II and then $50 \mu \mathrm{l}$ Stop and Glo Reagent (Promega) were added. Luminescence signal was measured with a $5 \mathrm{~s}$ delay for a period of $10 \mathrm{~s}$ in a Mithras LB 940 mutimode reader (Berthold Technologies, Bad Wildbad, Germany).

\section{Electrophoretic mobility shift assay}

Nuclear proteins were extracted from dispersed normal and $\mathrm{GH}_{3}$ pituitary cells using a NucBuster Protein Extraction Kit (Novagen, Madison, WI, USA). EMSA was conducted using a DIG gel shift kit (Roche Applied Science). Briefly, equal molar of CCAAT/Sp1UP and CCAAT/Sp1DN, or MutCCAAT/Sp1UP and MutCCAAT/Sp1DN were mixed and incubated at $95{ }^{\circ} \mathrm{C}$ for $10 \mathrm{~min}$. After slowly cooling down to room temperature, double-stranded (ds) oligonucleotides formed by annealing of the respective primers were diluted with TEN buffer $(10 \mathrm{mM}$ Tris-Cl, $1 \mathrm{mM}$ EDTA, and $0 \cdot 1 \mathrm{M}$ $\mathrm{NaCl}(\mathrm{pH} 8 \cdot 0)$ ) to a final concentration of $3.85 \mathrm{pmol} / \mu \mathrm{l}$. Labeling reaction was done in a final volume of $20 \mu \mathrm{l}$ containing $1 \mu \mathrm{l}$ ds-oligonucleotides, $9 \mu \mathrm{l}$ water, $4 \mu \mathrm{l} 5 \times$ labeling buffer, $4 \mu \mathrm{l} \mathrm{CoCl}_{2}$ solution, $1 \mu \mathrm{l}$ DIG-ddUTP, and $1 \mu \mathrm{l}$ terminal deoxynucleotide transferase. The reaction mixture was incubated at $37{ }^{\circ} \mathrm{C}$ for $15 \mathrm{~min}$ and chilled on ice immediately. Labeling reaction was stopped by $2 \mu$ EDTA ( $2 \mathrm{mM}$ ). The labeled ds-oligonucleotides were diluted to $0 \cdot 155 \mathrm{pmol} / \mu \mathrm{l}$ by adding $3 \mu \mathrm{l}$ double distilled water. For gel shift analysis, a small aliquot was further diluted to $15 \cdot 5 \mathrm{fmol} / \mu \mathrm{l}$. In the gel shift assay, $8 \mu \mathrm{g}$ nuclear extract from $\mathrm{GH}_{3}$ cells or normal pituitary cells were incubated with $4 \mu \mathrm{l}$ binding buffer (5 mM EDTA, $50 \mathrm{mM}\left(\mathrm{NH}_{4}\right)_{2} \mathrm{SO}_{4}, 5 \mathrm{mM}$ dithiothreitol
(DTT), 1\% Tween 20 (v/v), $150 \mathrm{mM} \mathrm{KCl}, 100 \mathrm{mM}$ Hepes $(\mathrm{pH} 7 \cdot 6)), 1 \mu \mathrm{l}$ poly $(\mathrm{dI}-\mathrm{dC})$, and $1 \mu \mathrm{l}$ poly-L-lysine. Double distilled water was added to a final reaction volume of $18 \mu \mathrm{l}$. In the competition and supershift assays, we added unlabeled ds-oligonucleotides and antibodies in the reaction mixture respectively. After 5-min incubation at room temperature, $2 \mu$ l DIG-labeled ds-oligonucleotides were added into the reaction mixture and incubated for another $30 \mathrm{~min}$. After adding $5 \mu$ loading dye, the reaction mixture was size-fractionated in a $6 \%$ DNA retardation gel (Invitrogen) in $0.5 \times$ TBE buffer and transblotted onto a positively charged nylon membrane for $2 \mathrm{~h}$ using an XCell II Blot Module (Invitrogen). The membrane was then u.v.-crosslinked using a Stratalinker 2400 (Stratagene, La Jolla, CA, USA), rinsed in washing buffer $(0 \cdot 1 \mathrm{M}$ maleic acid, $0 \cdot 15 \mathrm{M} \mathrm{NaCl}, 0 \cdot 3 \%$ Tween $20(\mathrm{pH} 7 \cdot 5)$ ) for $5 \mathrm{~min}$, and incubated for $30 \mathrm{~min}$ in blocking solution (1\% blocking reagent in maleic acid buffer). Following incubation with anti-DIG-AP (1:10 000) in blocking solution for $30 \mathrm{~min}$, the membrane was washed $2 \times 15 \mathrm{~min}$ in washing buffer and equilibrated in detection buffer $(0 \cdot 1 \mathrm{M}$ Tris- $\mathrm{HCl}, 0 \cdot 1 \mathrm{M} \mathrm{NaCl}(\mathrm{pH} 9 \cdot 5))$ for $5 \mathrm{~min}$. Chemiluminescence signals were detected with CSPD as the substrate in X-ray film.

\section{DNA affinity precipitation assay}

Ds-probes were generated by annealing biotin-labeled upstream oligonucleotides (Fig. 6) with the respective reverse-complemented oligonucleotides. Binding mixtures contained $10 \mu \mathrm{l}$ ds-probes $(10 \mu \mathrm{M}), 60 \mu \mathrm{g}$ nuclear protein extracted from $\mathrm{GH}_{3}$ cells, $80 \mu \mathrm{l}$ of $5 \times$ binding buffer (5 mM EDTA, $50 \mathrm{mM}\left(\mathrm{NH}_{4}\right)_{2} \mathrm{SO}_{4}, 5 \mathrm{mM}$ DTT, $1 \%$ Tween 20, $150 \mathrm{mM} \mathrm{KCl}$, and $100 \mathrm{mM}$ Hepes (pH 7.6)), and water to $400 \mu \mathrm{l}$. After incubation at $4{ }^{\circ} \mathrm{C}$ for $1 \mathrm{~h}$, $25 \mu \mathrm{l}$ Tetralink tetrameric avidin resin (Promega) was added to capture biotin-labeled DNA-protein complex. Resins were washed in $1 \times$ binding buffer for five times and proteins were eluted in $25 \mu$ l Novex Tris-glycine SDS sample buffer ( $2 \times$; Invitrogen). Eluted proteins were analyzed by Western blot.

\section{Site-directed mutagenesis}

The construct pGL3. (-516) was subjected to sitedirected mutagenesis by the QuikChange Site-Directed kit (Stratagene) and high fidelity PfuTurbo DNA polymerase (Stratagene). Reaction mixture was composed of $5 \mu \mathrm{l}$ of $10 \times$ reaction buffer, $20 \mathrm{ng}$ DNA template, $1 \mu \mathrm{l}$ of $10 \mathrm{mM}$ dNTPs, $1 \mu \mathrm{l}$ PfuTurbo polymerase, and $140 \mathrm{ng}$ PCR primers in a final volume of $50 \mu$ l. The reaction was initiated with a denaturing step at $95{ }^{\circ} \mathrm{C}$ for $30 \mathrm{~s}$, followed by PCR amplification with denaturation at $95{ }^{\circ} \mathrm{C}$ for $30 \mathrm{~s}$, annealing at $55^{\circ} \mathrm{C}$ for 
$1 \mathrm{~min}$, and extension at $68{ }^{\circ} \mathrm{C}$ for 6 min for a total of 16 cycles. Subsequently, the reaction mixture was cooled on ice and $1 \mu \mathrm{l}$ DpnI was added to digest the original DNA template for $2 \mathrm{~h}$ at $37{ }^{\circ} \mathrm{C}$. The PCR products were then precipitated with ethanol and used for transformation in XL1-Blue Supercompetent cells. Mutation was confirmed by DNA sequencing.

\section{Chromatin immunoprecipitation assay}

This assay was performed using ChIPs assay kit from Upstate (Waltham, MA, USA). Dispersed rat anterior pituitary normal cells and $\mathrm{GH}_{3}$ cells were cross-linked with $1 \%$ formaldehyde and suspended in lysis buffer ( $1 \%$ SDS, $10 \mathrm{mM}$ EDTA, and $50 \mathrm{mM}$ Tris-HCl $(\mathrm{pH} 8 \cdot 1))$. Lysates were then sonicated to shear DNA and diluted tenfold in ChIP dilution buffer $(0 \cdot 01 \%$ SDS, $1 \cdot 1 \%$ Triton X-100, 1.2 mM EDTA, $167 \mathrm{mM} \mathrm{NaCl}$, and $16.7 \mathrm{mM}$ Tris-HCl $(\mathrm{pH} 8 \cdot 1))$. The resultant chromatin was immunocleared with salmon sperm DNA/protein A agarose. Subsequently, $5 \mu$ l antibody against CBF/A (SC-13045) or Sp1(SC-14027) was incubated overnight with the chromatin at $4{ }^{\circ} \mathrm{C}$. The antibody/chromatin complex was pulled down by incubating with salmon sperm DNA/protein A agarose for $1 \mathrm{~h}$. Agarose was precipitated by gentle centrifugation and washed sequentially with low salt wash buffer $(0 \cdot 1 \%$ SDS, $1 \%$ Triton X-100, $2 \mathrm{mM}$ EDTA, $20 \mathrm{mM}$ Tris- $\mathrm{HCl}(\mathrm{pH} 8 \cdot 1)$, and $150 \mathrm{mM} \mathrm{NaCl}$ ), high salt wash buffer $(0 \cdot 1 \%$ SDS, $1 \%$ Triton X-100, $2 \mathrm{mM}$ EDTA, $20 \mathrm{mM}$ Tris-HCl (pH 8.1), and $500 \mathrm{mM} \mathrm{NaCl}$ ), $\mathrm{LiCl}$ wash buffer $(0.25 \mathrm{M} \mathrm{LiCl}, 1 \%$ IGELPAL-CA630, $1 \%$ sodium deoxycholic acid, $1 \mathrm{mM}$ EDTA, and $10 \mathrm{mM}$ Tris-HCl $(\mathrm{pH} 8 \cdot 1))$, and $1 \times \mathrm{TE}$. Histone complex was eluted in elution buffer ( $1 \%$ SDS and $0 \cdot 1 \mathrm{M} \mathrm{NaHCO}_{3}$ ) and heated at $65{ }^{\circ} \mathrm{C}$ for $6 \mathrm{~h}$ to reverse formaldehyde cross-linking. Samples were then treated with protease $\mathrm{K}$, followed by phenol extraction and ethanol precipitation. The DNA pellet was dissolved in $50 \mu \mathrm{l}$ Tris-EDTA buffer, and then $1 \mu \mathrm{l}$ DNA was used for PCR with 36 cycles of amplification. PCR amplification of soluble chromatin prior to immunoprecipitation was used as an input control.

\section{Data transformation and statistical analysis}

Promoter activities were expressed in firefly luciferase activity normalized against renilla luciferase activity in transfected $\mathrm{GH}_{3}$ and MH1C1 cells. The normalization was conducted to minimize the potential problems of variations in transfection efficiency among groups. Data presented were expressed as mean \pm s.E.M. and analyzed using Student's $t$-test. The differences were considered significant at $P<0 \cdot 05$.

\section{Results}

\section{Identification of $\alpha 1-s G C$ transcription start site}

Primer extension is a common method used to map the transcription start site. However, premature termination and intrinsic terminal transferase activity of reverse transcriptase make this method ineffective in some experiments (Gong \& Ge 2000). Since SMART RACE can reduce these problems (Gong \& Ge 2000), it was used in this study to identify the transcription start site of $\alpha 1-s G C$ gene. Pituitary mRNA was transcribed to cDNA with a gene-specific primer sGCaRT in the presence of BD SMART II A oligonucleotides and 5'-CDS primer. Amplification of cDNA with primers Universal Primer A Mix and RaceOuter produced a specific band with a size about 600 bp. Using primers Nested Universal Primer $\mathrm{A}$ and RaceInner, a specific band with a size around $400 \mathrm{bp}$ was obtained (data not shown) and subcloned into the TOPO TA cloning vector. Sequencing of five clones revealed that they possessed different $5^{\prime}$-ends (data not shown). The most upstream $5^{\prime}$-end, located at $287 \mathrm{bp}$ upstream of the start codon, was assigned as position +1 (Fig. 1). The respective clone contains the longest $5^{\prime}$-untranslated region (UTR) among other rat $\alpha 1$-sGC cDNA sequences (BC085746, NM_017090) and gene sequence (AF327645) deposited in the Genbank. Alignment between the cDNA sequence and the genome sequence of $\alpha 1$-s $G C$ gene indicated, it has a $183 \mathrm{bp}$ exon I and a $356 \mathrm{bp}$ exon II. In exon I, two nucleotides were different between cDNA sequence in this report and that in rat genome, possibly reflecting the presence of single nucleotide polymorphism (Fig. 1). The start codon is located in the exon II (Fig. 1).

\section{Exon I $+1$ agcetg ggaggagtgggagggactcggagcagcggggttctcacacacägccot ccaggcggtectcctccagtgcctgccagcccgaccccaaggcgaaga gcagcagtgctcagcccggggagtcctcgaagcgaagacacctgcgcc $\rightarrow$ Start of BC085746 \\ cggatgccectggectccegtgaccgcatcatg}

\section{Exon II}

atgctgggccactcgtgtctttgagtcagtagaagcagatcttcatca gtccacatcaacaccggctaataaggaggaaaccactgccaagctcca ggaacaccArGt tctgcaggaagt tcaaagatctcaagatcacggggg agtgtccttctccttactggctcctggtcaggttcctacggagccaa tagaggaggtggccggagtctctgagagctgccaggccactctgccca cctgccaggagtttgctgagaatgcagaagggagtcacccccaaagaa agacaagccgcaacagagtctacctacacaccctggcagagagtattg gcaagctcatttcccagag

Figure 1 Nucleotide sequence of the exons I and II of $\alpha 1$-sGC gene from rat anterior pituitary. The identified transcriptional start site is underlined and denoted as +1 . Nucleotides in exon I that mismatch with rat genome sequence were shown in italic bold. The position of the transcriptional start site previously reported (BC085746) is indicated by an arrow and the translational start codon in exon II is shown in capital bold. 


\section{Analysis of promoter activity in the $5^{\prime}$-flanking region}

Based on the genomic sequence in the rat genome reference database and the identified transcription start site, primers $\mathrm{Pt}(-3 \mathrm{~K})$ and $\mathrm{Pt}(156) \mathrm{R}$ were designed to amplify the $5^{\prime}$-promoter of $\alpha 1-s G C$ gene. These primers are located at -3529 to -3502 and 137 to 156 respectively. The obtained $3.067 \mathrm{~kb}$ fragment was cloned into pGL3.Basic vector and sequenced (GenBank accession: DQ141223). Sequence analysis of the promoter fragment revealed the presence of several putative cis-elements, including Sp1, CCAAT, Wilms' tumor, activator protein-1, and retinoid X-receptor (Fig. 2). Interestingly, no TATA box was found in the promoter. To identify region(s) critical for the transcription activity of $\alpha 1$-sGC, promoter constructs with different $5^{\prime}$-ends were prepared and the transfection was conducted in $\mathrm{GH}_{3}$ and MH1C1 cells. $\mathrm{GH}_{3}$ cells were derived from rat pituitary, express $\alpha 1$-sGC mRNA, and thus represent a good experimental cell model (Kostic et al. 2004); whereas MH1C1 is a valuable control model because of the lack of $\alpha 1$-sGC mRNA expression.

In RFL-6 rat fetal lung fibroblasts cells, sGC activity decreases significantly and rapidly with passage due to a downregulation of the $\alpha 1$ subunit mRNA (Kraft et al. 2004). To examine the possible effect of passage number on promoter activity, both 19th and 40th passages of $\mathrm{GH}_{3}$ cells were analyzed in this study. Using primers RTGC1 and RTGC2 (Table 1), the presence of

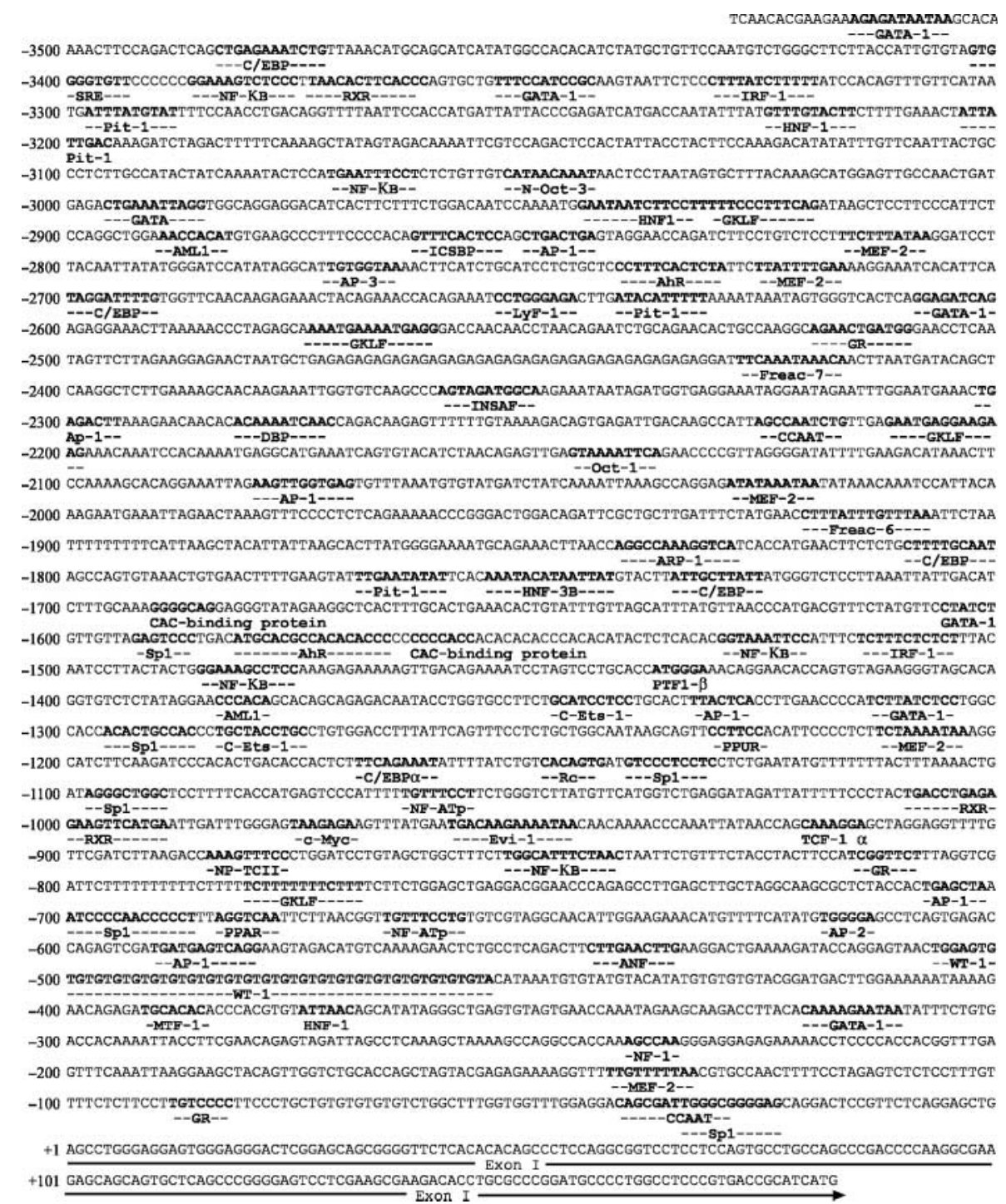

Figure 2 Nucleotide sequence of the promoter region of rat $\alpha 1$-sGC gene. Putative cis-elements are shown in bold, and annotated under the sequence. Non-mammalian originated elements were manually removed. The solid arrow indicates exon I. 
comparable $\alpha 1$-sGC mRNA levels was detected in two passages of $\mathrm{GH}_{3}$ cells (Fig. 3A), a feature that makes these cells a favorable model in $\alpha 1$-sGC studies. Furthermore, primers RTGC1 and RTGC2 were unable to amplify product using cDNA from $\mathrm{MH} 1 \mathrm{C} 1$, which was unlikely caused by cDNA qualify, because primers RTactin1 and RTactin2 (Table 1) amplified a strong PCR band (Fig. 3A). Therefore, MH1C1 cells represent a valuable control cell model for studies on $\alpha 1$-sGC mRNA expression.

In 19th passage of $\mathrm{GH}_{3}$ cells, the construct pGL3. (-3K), carrying 3529 bp promoter sequence of $\alpha 1$-sGC, has a similar promoter activity with the control vector pGL3.Basic. Deletion of the promoter fragments up to -49 in length induced biphasic changes in transcriptional activity. The deletion between -3529 and -2250 (construct pGL3. $(-2 \mathrm{~K})$ ) increased the promoter activity, indicating the presence of a negative

A

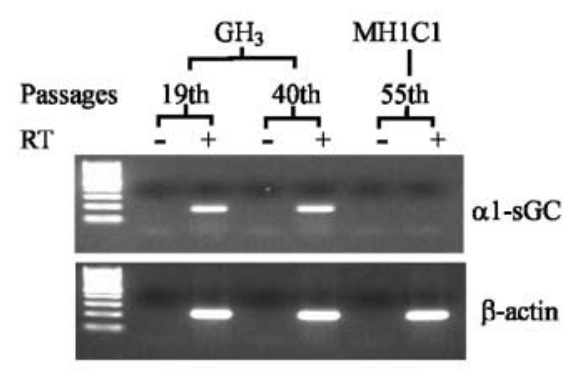

B

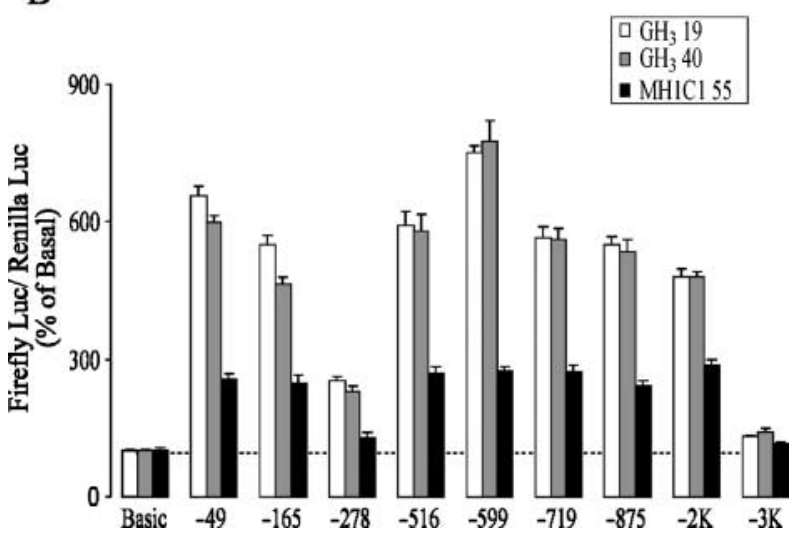

Figure 3 Promoter activity of $\alpha 1$-sGC deletion constructs. (A) Expression of $\alpha 1$-sGC mRNAs in $\mathrm{GH}_{3}$ immortalized pituitary and $\mathrm{MH} 1 \mathrm{C} 1$ liver cells. PCRs were conducted using $\alpha 1-\mathrm{sGC}$ specific primers and $\beta$-actin specific primers in the absence $(-)$ or presence $(+)$ of reverse transcription (RT). (B) Transient transfection analysis of deletion constructs. $\mathrm{GH}_{3}$ and $\mathrm{MH} 1 \mathrm{C} 1$ cells were cotransfected with renilla luciferase construct $\mathrm{pRL}-\mathrm{CMV}$ and firefly luciferase reporter constructs containing different size promoter fragments. Promoter activities for each construct were presented as a ratio of relative light units between firefly luciferase and renilla luciferase. Results are means \pm S.E.M. $(n=8)$. element(s) in this region. Further deletions until -516 have only a marginal effect on the promoter activity, indicating that the region between -2250 and -516 is not critical for basal sGC promote activity. Deletion of -516 to -278 and -278 to -165 sequences reduced and enhanced the promoter activity more than twofold respectively, indicating the presence of stimulatory and inhibitory elements in these regions (Fig. 3B). Deletion of the most proximal -49 region reduced the promoter activity more than sixfold, implying that this region is critical for the basal activity of $\alpha 1$-sGC promoter. We observed no significant difference among all promoter constructs examined in 19th and 40th passages of $\mathrm{GH}_{3}$ cells. In general, the $\alpha 1$-sGC promoter activities MH1C1 paralleled those observed in $\mathrm{GH}_{3}$ cells, but the amplitudes of responses were smaller (Fig. 3B).

\section{Characterization of CCAAT/Sp1 transcription-binding sites}

The most proximal -49 region contains the putative CCAAT/Sp1 cis-element (Fig. 2). To investigate the role of CCAAT/Sp1 site in basal promoter activity of $\alpha 1$-sGC, DNA-protein interaction was studied by EMSA. The synthesized oligonucleotides, CCAAT/Sp1UP and CCAAT/Sp1DN, located between -50 and -18 (Table 1), encompassed the CCAAT/Sp1 element completely. The annealed ds-oligonucleotide was named dsCCAAT/Sp1. Using DIG-labeled dsCCAAT/ Sp1 and nuclear extract from $\mathrm{GH}_{3}$ cells, EMSA revealed the presence of specific band in addition to the free probe (Fig. 4A, lane 1). The specific band was eliminated by the competition of unlabeled dsCCAAT/Sp1 in a dosedependent manner (Fig. 4A, lanes 2-4). Competition assay was also conducted using mutated dsCCAAT/Sp1. Analysis done by a transcription element search system (http://www.cbil.upenn.edu/tess/) indicated that this mutation renders the dsCCAAT/Sp1 loss of pattern of CCAAT and Sp1 elements. In this case, the competition with mutated dsCCAAT/Sp1 did not change the signal of the specific band (Fig. 4A, lanes 5-7). When nuclear proteins from normal anterior pituitary cells were used, one strong shifted band was observed (Fig. 4B, lane 1). This band was reduced by unlabeled dsCCAAT/Sp1 in a dose-dependent manner (Fig. 4B, lanes 2-4), but was not affected when the core sequence of dsCCAAT/Sp1 was mutated (Fig. 4B, lanes 5-7).

\section{Identification of transcriptional factors bound to CCAAT/Sp1 site}

To identify the transcriptional factors bound to the CCAAT/Sp1 site, the supershift analysis was conducted. In this experiment, antibodies against $\mathrm{CBF} / \mathrm{A}$, 
CCAAT/enhancer-binding protein, NF-1, and Sp1 were used. Three of these transcriptional factors, $\mathrm{CBF} / \mathrm{A}$, CCAAT/enhancer-binding protein, and NF-1, can bind with CCAAT element (Mantovani 1999). Using nuclear extract from $\mathrm{GH}_{3}$ cells, antibody against CBF/A reduced the specific signal of shifted bands, indicating the presence $\mathrm{CBF} / \mathrm{A}$ in the CCAAT/Sp1-nuclear protein complex (Fig. 5A, lane $\mathrm{CBF} / \mathrm{A}$ ). On the other
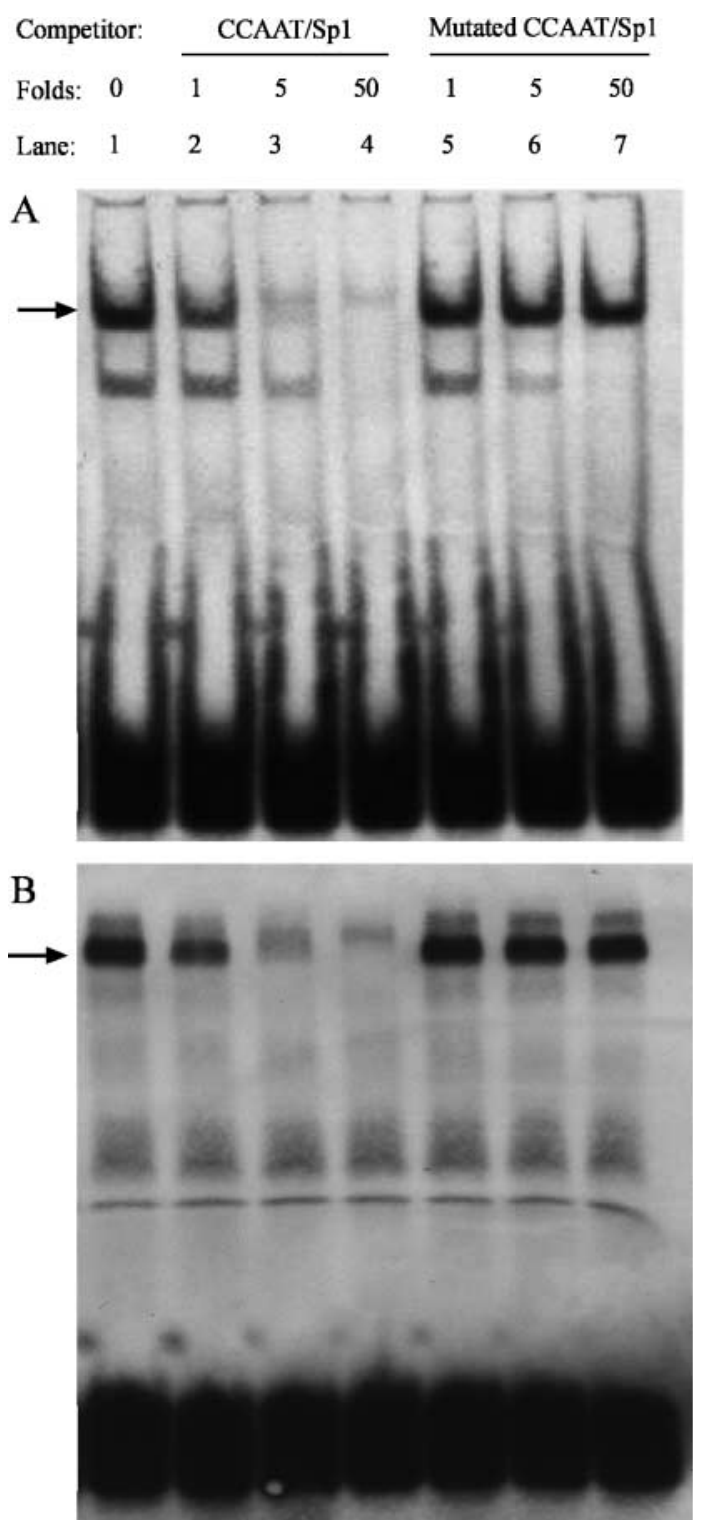

Figure 4 Analysis of protein complexes formed between putative CCAAT/Sp1 oligonucleotides and nuclear extracts from (A) $\mathrm{GH}_{3}$ and $(B)$ normal pituitary cells. Eight micrograms nuclear extracts were incubated with DIG-labeled putative CCAAT/Sp1 oligonucleotides in the absence of competitor (lane 1) and in the presence of different folds of unlabeled CCAAT/Sp1 oligonucleotides (lanes 2-4) or unlabeled mutated CCAAT/Sp1 oligonucleotides (lanes 5-7). Horizontal arrows indicate specific binding. hand, when antibody against Sp1 was used, a strong supershift band was observed (Fig. 5A, lane Sp1). Antibodies against CCAAT/enhancer-binding protein and NF-1 did not change the shifted bands (Fig. 5A,
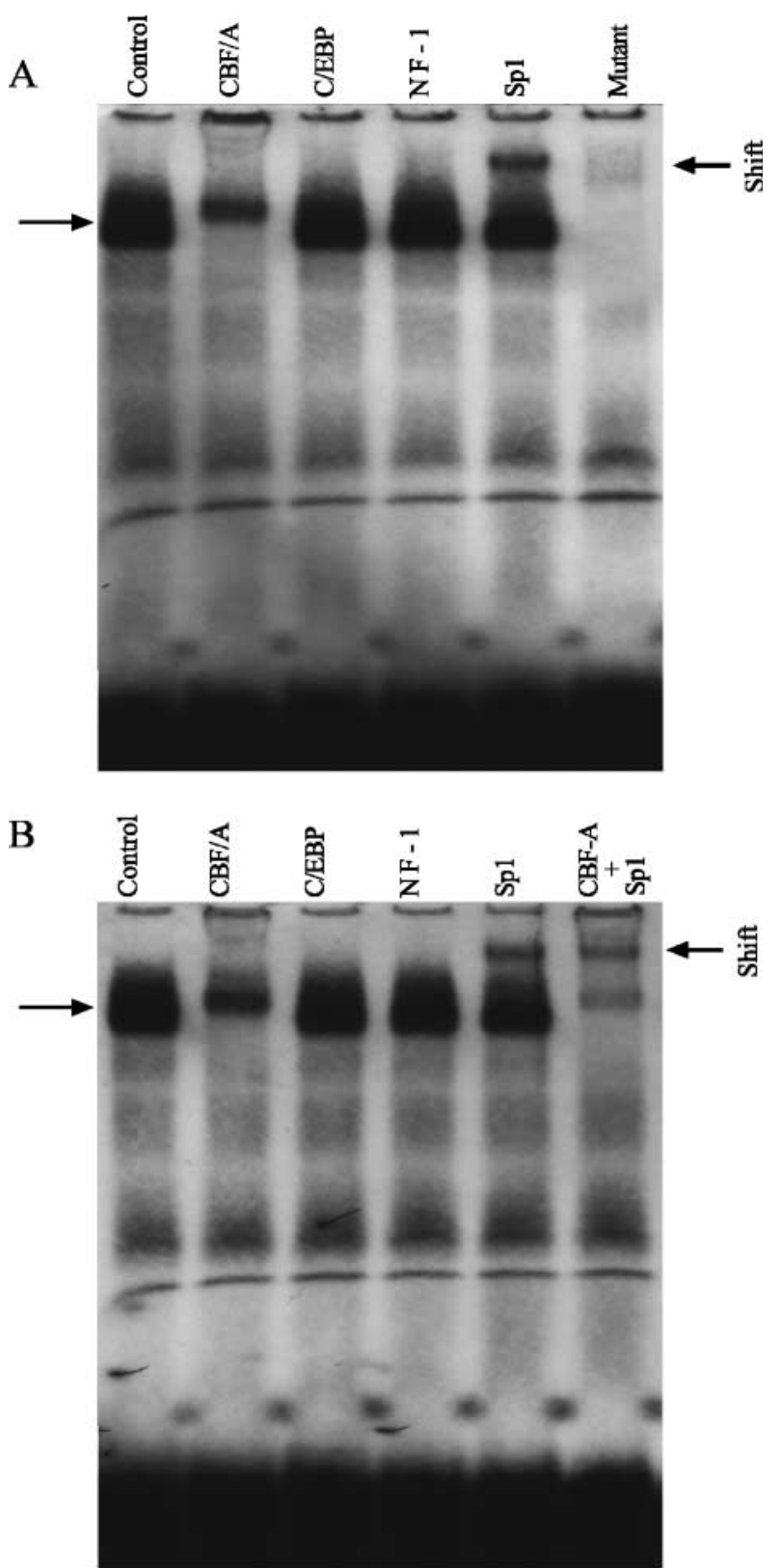

Figure 5 Identification of transcription factors binding with CCAAT/Sp1 oligonucleotides in (A) $\mathrm{GH}_{3}$ and (B) normal pituitary cells. Eight micrograms nuclear extracts were incubated with DIGlabeled putative CCAAT/Sp1 oligonucleotides in the absence of antibody (lane Control) or in the presence of different antibodies (lanes 2-5 in panel A and lanes 2-6 in panel B). Shifted bands are indicated with arrows. To confirm that binding sites for CBF/A and Sp1 are overlapping, $8 \mu \mathrm{g}$ nuclear extracts were also incubated with DIGlabeled mutated CCAAT/Sp1 oligonucleotides (lane 6 in panel A). C/EBP, CCAAT/enhancer-binding protein; NF-1, nuclear factor-1. 
lanes $\mathrm{C} / \mathrm{EBP}$ and NF-1). When labeled mutated dsCCAAT/Sp1 was used in EMSA, no shifted band was observed, indicating that the binding sites for Sp1 and CBF/A were overlapping (Fig. 5A, lane 6). Similar results were observed when nuclear extracts from the normal cells from rat pituitary were used in the assay (Fig. 5B). Furthermore, antibodies against $\mathrm{CBF} / \mathrm{A}$ and Sp1 have additive effects on the supershift result (Fig. 5B, lane $\mathrm{CBF} / \mathrm{A}+\mathrm{Sp} 1$ ), indicating $\mathrm{CBF} / \mathrm{A}$ and Sp1 can independently bind to the CCAAT/Sp1 element.

\section{Delineate nucleotides required for $\mathrm{CBF}$ and Sp1 binding}

To precisely delineate nucleotides required for CBF/A and Sp1 binding, DNA affinity precipitation assay was conducted using a series of mutated ds-oligonucleotides, termed mutants 1-8 (Fig. 6, upper panel). The upstream oligonucleotides of wild type has the same sequence as primer CCAAT/Sp1UP, located at -50 to -18 , and mutant 5 in this experiment has the same sequence as the above-mentioned primer MutCCAAT/ Sp1UP. When Sp1 antibody was used, signals in mutants 5-8 were weaker than that in the wild type (Fig. 6, panel Sp1), indicating that the region between -35 and -26 was important for Sp1 binding. On the other hand, when CBF/A antibody was used, signals in mutants 3-6 were much weaker than that in the wild type (Fig. 6, panel $\mathrm{CBF} / \mathrm{A}$ ), indicating that the region between -39 and -30 was important for CBF binding. Clearly, the CCAAT and Sp1 cis-elements are partly overlapping because mutation in the region between -35 and -30 reduced the affinity for both CBF/A and Sp1 binding (Fig. 6).

\section{Inhibition of transcription by mutation of CCAAT/Sp1 element}

To clarify the potential role of CCAAT and Sp1 cis-element in basal promoter activity of $\alpha 1$-s $G C$ gene, mutagenesis analysis was conducted. The CCAAT and Sp1 sites in construct pGL3. $(-516)$ was mutated to pGL3. (-516Mut3), pGL3.(-516Mut5), pGL3. $(-516 \mathrm{Mut} 7)$ according to the sequences of mutant 3 , 5 , and 7 respectively. Mutant 3 has a reduced affinity to $\mathrm{CBF} / \mathrm{A}$ but not to Sp1, whereas mutant 7 has a reduced affinity to Sp1 but not to CBF/A (Fig. 6). Mutant 5 has the weakest affinity to both $\mathrm{CBF} / \mathrm{A}$ and Sp1 (Fig. 6). Comparing with the promoter activity of pGH3. $(-516)$, all three mutant constructs had a weaker promoter activity, demonstrating that both CCAAT and Sp1 ciselements were stimulatory to the basal activity of $\alpha 1$-sGC promoter (Fig. 7).

\section{WT

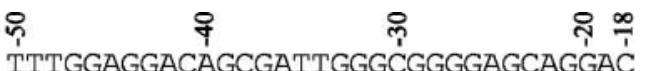

Mutant 1 TTTGGAAAACAGCGATTGGGCGGGGAGCAGGAC

Mutant 2 TTTGGAGGAAAACGATTGGGCGGGGAGCAGGAC

Mutant 3 TTTGGAGGACAAAAATTGGGCGGGGAGCAGGAC

Mutant 4 TTTGGAGGACAGCAAAAGGGCGGGGAGCAGGAC

Mutant 5 TTTGGAGGACAGCGAAAAAGCGGGGAGCAGGAC

Mutant 6 TTTGGAGGACAGCGATTAAAAGGGGAGCAGGAC

Mutant 7 TTTGGAGGACAGCGATTGGAAAAGGAGCAGGAC

Mutant 8 TTTGGAGGACAGCGATTGGGCAAAAAGCAGGAC

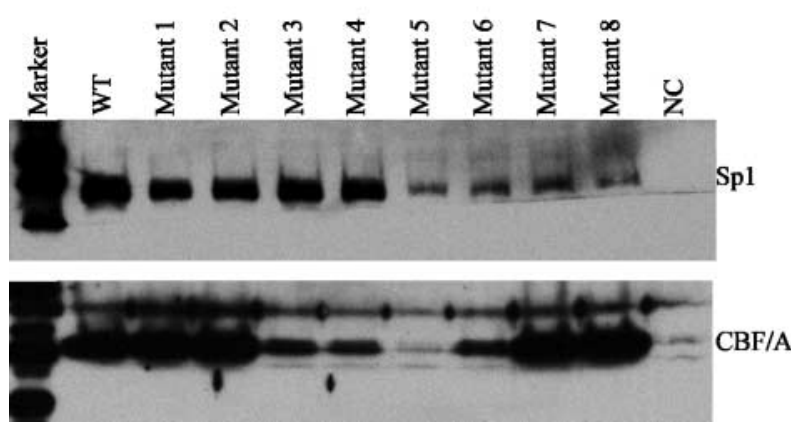

Figure 6 Delineation of nucleotides required for CBF/A and $\mathrm{Sp} 1$ binding. Sixty micrograms nuclear extracts from $\mathrm{GH}_{3}$ cells were incubated with ds-oligonucleotides with biotin labeling on one strand. Bound proteins were pulled down by avidin resin and analyzed by western blot. Upper panel shows the biotin-labeled strand and mutated nucleotides were indicated in bold. WT, wild type; NC, negative control (the biotin-labeled scramble ds-oligonucleotides).

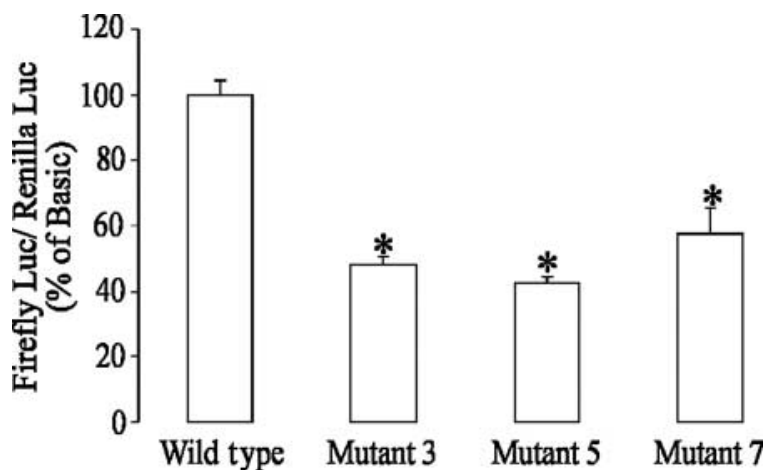

Figure 7 Effects of CCAAT/Sp1 site mutation on the promoter activity of $\alpha 1$-sGC in $\mathrm{GH}_{3}$ cells. Construct pGL3-sGC(-516) was used to prepare mutation constructs pGL3-sGC(Mutant 3), pGL3-sGC(Mutant 5), and pGL3-sGC(Mutant 7). $\mathrm{GH}_{3}$ cells were transfected with renilla luciferase construct $\mathrm{pRL}-\mathrm{CMV}$ and different firefly luciferase reporter constructs. Promoter activity for each construct was presented as the ratio of relative light units between firefly luciferase and renilla luciferase. Results are means \pm S.E.M. $(n=8)$ and asterisks indicate significant difference when compared with the wild-type pGL3-sGC $(-516 ; P<0.05)$. 


\section{Recruitment of Sp1 and CBF/A to the promoter of $\alpha 1$-sGC gene in vivo}

To investigate whether both Sp1 and CBF/A can be recruited to the CCAAT/Sp1 element in vivo, ChIP was conducted in $\mathrm{GH}_{3}$ and normal pituitary cells. Four primer pairs were designed to amplify different regions of $\alpha 1$-sGC promoter. Primers $\operatorname{IPt}(-3 \mathrm{~K}) \mathrm{UP}$ and $\operatorname{IPt}(-3 \mathrm{~K}) \mathrm{DN}$ were used to amplify a $115 \mathrm{bp}$ fragment located $3 \mathrm{~kb}$ upstream of CCAAT/Sp1 site, and primers $\operatorname{IPt}(-1 \mathrm{~K}) \mathrm{UP}$ and $\operatorname{IPt}(-1 \mathrm{~K}) \mathrm{DN}$ were used to amplify a $138 \mathrm{bp}$ fragment located $1 \mathrm{~kb}$ upstream of CCAAT/Sp1 site (Table 1). On the other hand, primer pairs $\operatorname{IPt}(-165) \mathrm{UP}$ and $\operatorname{IPt}(-18) \mathrm{DN}, \operatorname{IPt}(-63) \mathrm{UP}$, and $\operatorname{IPt}(59) \mathrm{DN}$ cover the CCAAT/Sp1 region (Fig. 8, lower panel). PCR products were only analyzed in a qualitative manner. $\mathrm{In}_{\mathrm{GH}_{3}}$ chromatin, all these primers amplified a specific product with the predicted size using the input DNA as the template (Fig. 8A, Input). When the chromatin was immunoprecipitated by antibody against the $\mathrm{CBF} / \mathrm{A}$, no PCR product was found using first primer pairs (Fig. 8A, CBF/A, lane 1), and only a weak signal appeared using second primer pairs (Fig. 8A, CBF/A, lane 2). In agreement with the presence of $\mathrm{CBF} / \mathrm{A}$ binding in the region between -41 and -32 , third and fourth primer pairs generated specific PCR products (Fig. 8A, CBF/A, lanes 3 and 4). When the chromatin was immunoprecipitated with antibody against Sp1, a strong PCR amplification was also observed using primer pairs covering the CCAAT/ Sp1 element (Fig. 8A, Sp1, lanes 3 and 4). No or weak
PCR amplification was detected using primer pairs distal to the CCAAT/Sp1 element (Fig. 8A, Sp1, lanes 1 and 2). The PCR amplification was specific because no amplicon was observed when chromatin was precipitated with immunoglobulin $\mathrm{G}$ as the negative control (Fig. 8A, IgG). Similar results were observed in normal pituitary cells (Fig. 8B).

\section{Discussion}

Using normal cells from rat pituitary, we identified the transcription start site and cloned the $3.5 \mathrm{~kb}$ upstream promoter sequence of rat $\alpha 1$-sGC subunit gene. For the first time, we also characterized the promoter of $\alpha 1$-sGC subunit gene in this species. The data showed that the transcription start site of rat $\alpha 1$-sGC is located at $287 \mathrm{bp}$ upstream of the start codon in mRNA, which enabled us to define the boundary of $5^{\prime}$-UTR and promoter. Our sequence analysis indicated that the cloned promoter of rat $\alpha 1$-sGC subunit belongs to the TATAless promoters and possesses several putative transcription factor-binding sites, including Sp1, CCAAT, Wilms' tumor, and activator protein-1. The results further revealed that CCAAT box and Sp1 cis-element were crucial in the regulation of $\alpha 1$-sGC promoter activity in this species. These elements may also provide a crosstalk mechanism between different components in the $\mathrm{NO} / \mathrm{sGC}$ signaling pathway by regulating the transcription efficiency of $\beta 1$-sGC and NO synthases.

\section{A}

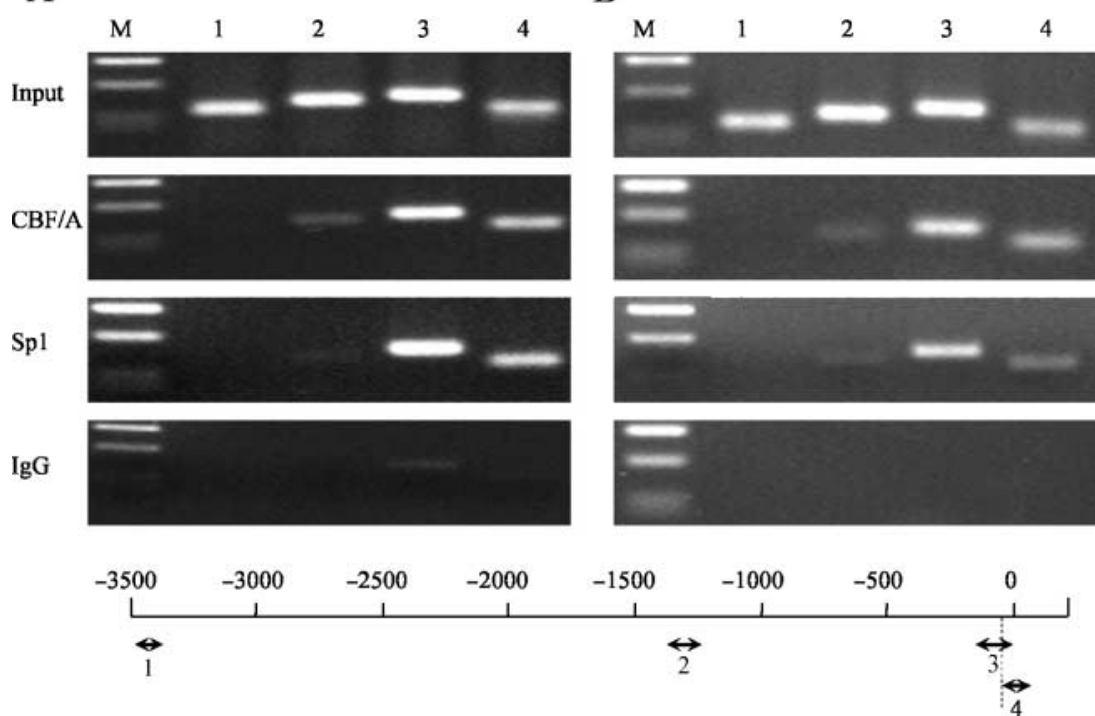

Figure 8 Recruitment of CBF/A and Sp1 transcription factors to the $\alpha 1$-sGC promoter in (A) $\mathrm{GH}_{3}$ and (B) normal pituitary cells. Soluble chromatin from $\mathrm{GH}_{3}$ cells or normal cells was precipitated with antibodies against CBF/A, Sp1, or preimmune rabbit immunoglobulin (IgG). The DNA size marker is labeled M. DNA regions analyzed in PCR (lanes 1-4) are schematically represented at the bottom. The predicted overlapping binding site for $\mathrm{CBF} / \mathrm{A}$ and $\mathrm{Sp} 1$ is indicated by vertical dotted line. 
The sequence analysis indicated that the cloned promoter of rat $\alpha 1$-sGC subunit belong to the TATA-less promoters. The promoter of mouse $\alpha 1$-sGC (VazquezPadron et al. 2004) and human $\beta 1$-sGC (Sharina et al. 2003) subunit genes also lacks a TATA box. In general, the TATA-like element is crucial for the accurate transcription initiation in the protein-coding gene (Smale 1997). Consistently, our results also revealed the presence of different transcription initiation sites among different clones. However, a special scenario exists in medaka fish, where only a single transcriptional start site was identified in different tissues despite the absence of functional TATA-like element in the promoter of $\alpha 1$-sGC (Yamamoto \& Suzuki 2002).

Our transient transfection experiments confirmed that the cloned promoter of $\alpha 1$-sGC subunit exhibits low activity in resting cells and identified elements that could contribute to it. The maximal transcription activity was obtained when a $599 \mathrm{bp}$ promoter fragment was inserted in the luciferase construct. In another study, it was shown that the transcriptional activity increased twofold when a $1.6 \mathrm{~kb}$ mouse $\alpha 1$-sGC promoter sequence was inserted in the promoterless construct and expressed in NIE-115 cells, whereas the transcriptional activity increased $4 \cdot 6$-fold when a $1 \cdot 4 \mathrm{~kb}$ mouse $\beta 1$-sGC promoter sequence was inserted (Sharina et al. 2000). Our deletion analysis demonstrated that a putative inhibitory element might exist in the region between -2 and $-3 \mathrm{~kb}$. In this region, several putative cis-elements were identified, which can bind with transcription factors, including the glucocorticoid receptor, hepatocyte NF-1, GATA, retinoid X receptor, and CCAAT/enhancer-binding protein. Notably, glucocorticoid receptor can interact with corepressors, such as nuclear receptor corepressor and silencing mediator of retinoid and thyroid receptors, and reduce gene expression (Wang et al. 2004).

The expression of $\alpha 1$-sGC mRNA is cell specific. In mice, the highest expression level of $\alpha 1$-sGC mRNAs was observed in lung, and the lowest levels in liver, muscle, and ileum (Mergia et al. 2003). In the present study, RT-PCR was unable to detect $\alpha 1$-sGC mRNA in a liverderived cell line MH1C1. Furthermore, the activities of promoters more proximal to $-2 \mathrm{~kb}$ in $\mathrm{MH} 1 \mathrm{Cl} 1$ cells were much weaker than that in $\mathrm{GH}_{3}$ cells, indicating that the lack of $\alpha 1$-sGC expression in MH1C1 cells may partly result from reduced proximal promoter activity. However, the elements and the $3.5 \mathrm{~kb}$ region so far reported are not enough to achieve the cell-specific expression of $\alpha 1$-sGC, since the promoter activity of pGL3. $(-3 \mathrm{~K})$ was similar in different cell lines. We have examined the possible involvement of DNA methylation and histone modifications in transcriptional regulation of $\alpha 1$-sGC mRNA. Treatment with DNA demethylating reagent 5-azacytidine or histone deacetylase inhibitor trichostatin A did not change the $\alpha 1$-sGC mRNA level in
$\mathrm{GH}_{3}$ cells (data not shown), indicating that the epigenetic regulation does not contribute to the expression of $\alpha 1$-sGC mRNA in $\mathrm{GH}_{3}$ cells.

The coexpression of $\alpha 1$ - and $\beta 1$-sGC subunits is required to obtain a functional enzyme, implying that the expression of both subunits is coordinated. As a matter of fact, the expression of $\alpha 1$ and $\beta 1$ subunits is tightly coregulated (Nedvetsky et al. 2002). However, variable mechanisms may account for coregulation of two subunits in different animal models. In medaka fish, $\alpha 1$ - and $\beta 1$-s $G C$ genes are $986 \mathrm{bp}$ apart and organized in tandem in the genome. The expression of both subunits is directly coordinated by the $5^{\prime}$-upstream region of $\alpha 1$ sGC subunit (Mikami et al. 1999). This is not the case with mammalian species. According to the National Center for Biotechnology Information database, $\alpha 1$ and $\beta 1$ subunits are separated by 60 and $43 \mathrm{~kb}$ in mouse and human respectively. In mouse, the extended region comprises $2 \%$ of the total chromosomal length (Sharina et al. 2000). In rat, genes for $\alpha 1$ - and $\beta 1$-sGC subunits have been mapped to chromosome 2 and linked to known quantitative trait locus markers of salt-sensitive hypertension in the Dahl rats (Azam et al. 1998), and two subunits are separated by $19 \mathrm{~kb}$ (NCBI data).

The coordination of transcriptional regulation of two subunits in mammals may be achieved by sharing some common transcription factor-binding sites, such as CCAAT box. Proteins that can bind with CCAAT box include CBF, NF-1, CCAAT/enhancer-binding protein, and CCAAT displacement protein (Mantovani 1999). Furthermore, $\mathrm{CBF}$ is composed of three subunits, $\mathrm{CBF}$ / $\mathrm{A}, \mathrm{CBF} / \mathrm{B}$, and $\mathrm{CBF} / \mathrm{C}$, which are required for $\mathrm{DNA}$ binding. The binding of CBF with CCAAT box can result in the disruption of nucleosome and transcription activation (Coustry et al. 2001). In the promoter of $\beta 1$-sGC gene in human, the CCAAT box can bind with $\mathrm{CBF}$ and enhance promoter activity (Sharina et al. 2003). In this study, we also identified the CCAAT box in $\alpha 1$-sGC promoter at region between -50 and -18 , which can interact with the transcription factor $\mathrm{CBF}$. Moreover, the region between -39 and -30 is most critical for this interaction. Disruption of the CBFCCAAT interaction resulted in twofold decrease in promoter activity. Therefore, CCAAT box conferred the stimulatory effect on both $\alpha 1$ - and $\beta 1$-sGC promoter activities. The in vivo binding of CBF with this segment was confirmed by ChIP assay, providing a mechanism to coordinate the gene expression of $\alpha 1-$ and $\beta 1$-sGC subunits. The binding of CCAAT displacement protein to this site was not examined, because it normally acts as an inhibitory factor (Nishio \& Walsh 2004).

Our results also demonstrated that $\mathrm{Sp} 1$ is involved in the transcription regulation of $\alpha 1$-sGC subunit gene. In this case, the region between -35 and -26 is important for the DNA-protein interaction. A mutant with reduced affinity to $\mathrm{Sp} 1$ exhibited lower promoter activity 
than wild type. As the founding member of the family of zinc finger transcription factors, Sp1 participates in a wide variety of physiological processes, including the cell-cycle regulation and hormonal activity (Chu \& Ferro 2005). In the NO/sGC signaling pathways, Sp1 is important for the basal activity of endothelial (Wu 2002) and neuronal (Saur et al. 2002, Bachir et al. 2003) $\mathrm{NO}$ synthases. Moreover, it is also involved in the regulation of human type I protein kinase $G$ gene expression (Sellak et al. 2002). Together with the findings presented here, these observations indicated the importance of Sp1 in the NO/sGC signaling.

The binding sites for $\mathrm{CBF}$ and $\mathrm{Sp} 1$ are overlapping in the region between -35 and -30 , which implies the cooperation between $\mathrm{CBF}$ and $\mathrm{Sp} 1$ in the transcriptional regulation of $\alpha 1$-sGC subunit gene. In our experiments, mutation of the overlapping region resulted in the highest reduction in the promoter activity. In the promoter of rat fatty acid synthase, an insulin-responsive element (IRE) was composed of a CCAAT element and a Sp1 element with $10 \mathrm{bp}$ in distance. Using IRE as the probe, three kinds of DNA-protein complex were formed: IRE:Sp1, IRE:CBF, and IRE:Sp1:CBF. The cooperation of Sp1 and CBF increased the stability of DNA-protein complex (Roder et al. 1997). Because the distance between $\mathrm{CBF}$ and Sp1 seems to be critical for the synergism of CBF and Sp1 (Alimov et al. 2005), their relationship in the control of $\alpha 1$-sGC subunit gene expression remains to be proven.

\section{Acknowledgements}

We are thankful to Chon-Hwa Tsai-Morris for helpful suggestions.

\section{Funding}

This research was supported by the Intramural Research Program of the National Institute of Child Health and Human Development, National Institutes of Health. The authors declare that there is no conflict of interest that would prejudice the impartiality of this scientific work.

\section{References}

Alimov AP, Park-Sarge OK, Sarge KD, Malluche HH \& Koszewski NJ 2005 Transactivation of the parathyroid hormone promoter by specificity proteins and the nuclear factor Y complex. Endocrinology 146 3409-3416.

Azam M, Gupta G, Chen W, Wellington S, Warburton D \& Danziger RS 1998 Genetic mapping of soluble guanylyl cyclase genes: implications for linkage to blood pressure in the Dahl rat. Hypertension 32 149-154.

Bachir LK, Garrel G, Lozach A, Laverriere JN \& Counis R 2003 The rat pituitary promoter of the neuronal nitric oxide synthase gene contains an Sp1-, LIM homeodomain-dependent enhancer and a distinct bipartite gonadotropin-releasing hormone-responsive region. Endocrinology 144 3995-4007.

Baltrons MA, Pedraza CE, Heneka MT \& Garcia A 2002 Beta-amyloid peptides decrease soluble guanylyl cyclase expression in astroglial cells. Neurobiology of Disease 10 139-149.

Baltrons MA, Pifarre P, Ferrer I, Carot JM \& Garcia A 2004 Reduced expression of NO-sensitive guanylyl cyclase in reactive astrocytes of Alzheimer disease, Creutzfeldt-Jakob disease, and multiple sclerosis brains. Neurobiology of Disease 17 462-472.

Bauersachs J, Bouloumie A, Mulsch A, Wiemer G, Fleming I \& Busse R 1998 Vasodilator dysfunction in aged spontaneously hypertensive rats: changes in NO synthase III and soluble guanylyl cyclase expression, and in superoxide anion production. Cardiovascular Research 37 772-779.

Bauersachs J, Bouloumie A, Fraccarollo D, Hu K, Busse R \& Ertl G 1999 Endothelial dysfunction in chronic myocardial infarction despite increased vascular endothelial nitric oxide synthase and soluble guanylate cyclase expression: role of enhanced vascular superoxide production. Circulation 100 292-298.

Budworth J, Meillerais S, Charles I \& Powell K 1999 Tissue distribution of the human soluble guanylate cyclases. Biochemical and Biophysical Research Communications 263 696-701.

Chu S \& Ferro TJ 2005 Sp1: regulation of gene expression by phosphorylation. Gene 348 1-11.

Coustry F, Hu Q, de Crombrugghe B \& Maity SN 2001 CBF/NF-Y functions both in nucleosomal disruption and transcription activation of the chromatin-assembled topoisomerase IIalpha promoter. Transcription activation by CBF/NF-Y in chromatin is dependent on the promoter structure. Journal of Biological Chemistry 276 40621-40630.

De Frutos S, Saura M, Griera M, Rivero-Vilches FJ, Zaragoza C, Rodriguez-Puyol D \& Rodriguez-Puyol M 2005 Differential regulation of soluble guanylyl cyclase expression and signaling by collagens: involvement of integrin-linked kinase. Journal of the American Society of Nephrology 16 2626-2635.

Garbers DL, Koesling D \& Schultz G 1994 Guanylyl cyclase receptors. Molecular Biology of the Cell 5 1-5.

Gong B \& Ge R 2000 Using the SMART cDNA system to map the transcription initiation site. Biotechniques 28 846-852.

Hanafy KA, Martin E \& Murad F 2004 CCTeta, a novel soluble guanylyl cyclase-interacting protein. Journal of Biological Chemistry $\mathbf{2 7 9}$ 46946-46953.

Humbert P, Niroomand F, Fischer G, Mayer B, Koesling D, Hinsch KD, Gausepohl H, Frank R, Schultz G \& Bohme E 1990 Purification of soluble guanylyl cyclase from bovine lung by a new immunoaffinity chromatographic method. European Journal of Biochemistry 190 273-278.

Kloss S, Bouloumie A \& Mulsch A 2000 Aging and chronic hypertension decrease expression of rat aortic soluble guanylyl cyclase. Hypertension 35 43-47.

Kloss S, Srivastava R \& Mulsch A 2004 Down-regulation of soluble guanylyl cyclase expression by cyclic AMP is mediated by mRNAstabilizing protein HuR. Molecular Pharmacology 65 1440-1451.

Kostic TS, Tomic M, Andric SA \& Stojilkovic SS 2002 Calciumindependent and cAMP-dependent modulation of soluble guanylyl cyclase activity by $\mathrm{G}$ protein-coupled receptors in pituitary cells. Journal of Biological Chemistry 277 16412-16418.

Kostic TS, Andric SA \& Stojilkovic SS 2004 Receptor-controlled phosphorylation of alpha 1 soluble guanylyl cyclase enhances nitric oxide-dependent cyclic guanosine 5'-monophosphate production in pituitary cells. Molecular Endocrinology 18 458-470.

Kraft PJ, Haynes-Johnson D, Bhattacharjee S, Lundeen SG \& Qiu Y 2004 Altered activities of cyclic nucleotide phosphodiesterases and soluble guanylyl cyclase in cultured RFL-6 cells. International Journal of Biochemistry and Cell Biology 36 2086-2095.

Krumenacker JS, Hyder SM \& Murad F 2001 Estradiol rapidly inhibits soluble guanylyl cyclase expression in rat uterus. PNAS 98 717-722. 
Lorens JB, Nerland AH, Aasland R, Lossius I \& Male R 1993 Expression of growth hormone genes in Atlantic salmon. Journal of Molecular Endocrinology 11 167-179.

Mantovani R 1999 The molecular biology of the CCAAT-binding factor NF-Y. Gene 239 15-27.

Mergia E, Russwurm M, Zoidl G \& Koesling D 2003 Major occurrence of the new alpha2betal isoform of NO-sensitive guanylyl cyclase in brain. Cellular Signalling 15 189-195.

Mikami T, Kusakabe T \& Suzuki N 1999 Tandem organization of medaka fish soluble guanylyl cyclase alphal and betal subunit genes. Implications for coordinated transcription of two subunit genes. Journal of Biological Chemistry 274 18567-18573.

Nedvetsky PI, Kleinschnitz C \& Schmidt HH 2002 Regional distribution of protein and activity of the nitric oxide receptor, soluble guanylyl cyclase, in rat brain suggests multiple mechanisms of regulation. Brain Research 950 148-154.

Nishio H \& Walsh MJ 2004 CCAAT displacement protein/cut homolog recruits G9a histone lysine methyltransferase to repress transcription. PNAS 101 11257-11262.

Okita K, Nobuhisa I, Takizawa M, Ueno M, Kimura N \& Taga T 2003 Genomic organization and characterization of the mouse ELYS gene. Biochemical and Biophysical Research Communications 305 327-332.

Pedraza CE, Baltrons MA, Heneka MT \& Garcia A 2003 Interleukin-1 beta and lipopolysaccharide decrease soluble guanylyl cyclase in brain cells: NO-independent destabilization of protein and NO-dependent decrease of mRNA. Journal of Neuroimmunology 144 80-90.

Pyriochou A \& Papapetropoulos A 2005 Soluble guanylyl cyclase: more secrets revealed. Cellular Signalling 17 407-413.

Roder KH, Wolf SS, Beck KF \& Schweizer M 1997 Cooperative binding of NF-Y and Sp1 at the DNase I-hypersensitive site, fatty acid synthase insulin-responsive element 1 , located at -500 in the rat fatty acid synthase promoter. Journal of Biological Chemistry 272 21616-21624.

Salgado MC, Meton I, Egea M \& Baanante IV 2004 Transcriptional regulation of glucose-6-phosphatase catalytic subunit promoter by insulin and glucose in the carnivorous fish, Sparus aurata. Journal of Molecular Endocrinology 33 783-795.

Saur D, Seidler B, Paehge H, Schusdziarra V \& Allescher HD 2002 Complex regulation of human neuronal nitric-oxide synthase exon 1c gene transcription. Essential role of Sp and ZNF family members of transcription factors. Journal of Biological Chemistry 277 25798-25814.

Sellak H, Yang X, Cao X, Cornwell T, Soff GA \& Lincoln T 2002 Sp1 transcription factor as a molecular target for nitric oxide- and cyclic nucleotide-mediated suppression of cGMP-dependent protein kinase-Ialpha expression in vascular smooth muscle cells. Circulation Research 90 405-412.

Sharina IG, Krumenacker JS, Martin E \& Murad F 2000 Genomic organization of alphal and betal subunits of the mammalian soluble guanylyl cyclase genes. PNAS 97 10878-10883.

Sharina IG, Martin E, Thomas A, Uray KL \& Murad F 2003 CCAATbinding factor regulates expression of the betal subunit of soluble guanylyl cyclase gene in the BE2 human neuroblastoma cell line. PNAS 100 11523-11528.

Smale ST 1997 Transcription initiation from TATA-less promoters within eukaryotic protein-coding genes. Biochimica et Biophysica Acta 1351 73-88.

Taylor TA, Pollock JS \& Pollock DM 2003 Down-regulation of soluble guanylyl cyclase in the inner medulla of DOCA-salt hypertensive rats. Vascular Pharmacology 40 155-160.

Vazquez-Padron RI, Pham SM, Pang M, Li S \& Aitouche A 2004 Molecular dissection of mouse soluble guanylyl cyclase alphal promoter. Biochemical and Biophysical Research Communications 314 208-214.

Wang Q, Blackford JA Jr, Song LN, Huang Y, Cho S \& Simons SS Jr 2004 Equilibrium interactions of corepressors and coactivators with agonist and antagonist complexes of glucocorticoid receptors. Molecular Endocrinology 18 1376-1395.

Wu KK 2002 Regulation of endothelial nitric oxide synthase activity and gene expression. Annals of the New York Academy of Sciences 962 $122-130$.

Yamamoto T \& Suzuki N 2002 Promoter activity of the 5'-flanking regions of medaka fish soluble guanylate cyclase alphal and betal subunit genes. Biochemical Journal 361 337-345.

Zabel U, Weeger M, La M \& Schmidt HH 1998 Human soluble guanylate cyclase: functional expression and revised isoenzyme family. Biochemical Journal 335 51-57.

Received 29 August 2006

Accepted 12 September 2006 